\title{
A History of Narrative Film
}

\author{
By Jan Uhde \\ Fall 1996 Issue of KINEMA
}

A CURSORY EXAMINATION of the Third edition of David Cook's film history already reveals an impressive publication. The more then a thousand pages of dense text include 1,500 colour and monochrome illustrations, a glossary with 250 terms, a bibliography of over 2,000 titles on the history and theory of cinema, and an extensive index. This new edition does not fundamentally change Cook's approach used in the earlier editions (1981 and 1990) -- it simply makes the good even better.

Examining narrative film medium's history from its inception up to the mid 1990s, Cook has thoroughly updated the entire text, including the bibliography; he has also added several new sections, such as those on ethnic cinema, Scandinavian and New Spanish cinema. Particularly commendable is the inclusion of many inadequately explored or neglected spots on the world film map: Baltic (Lithuania, Latvia, Estonia); Transcaucasian (Georgia, Armenia, Azerbaijan); Central Asian (Uzbekistan, Kazakhstan, Kirghizia, Tadjikistan, Turkmenistan) cinemas, as well as the film productions of the Middle Eastern countries and those of the Pacific Rim. This marks Cook's perspective as genuinely global, an approach missing in many film-historical publications which suffer from crippling Eurocentric or North American parochial tunnel vision.

Perhaps the author's most important talent is his ability to provide a succinct and precise evaluation of a filmmaker, a movement, a trend, or a national cinema, without losing the essence of the examined matter and the necessary historical, political, social, economical and personal contexts. This is an absolute necessity in respect to the gargantuan task of condensing one hundred years of motion pictures' evolution into one volume. Despite the mountains of data which Cook has to cope with, the result is a remarkably readable text which can be equally appreciated by a film scholar, and an astute reader alike.

The author of A History of Narrative Film must also be complimented for his factual consistency and precision, including details such as the spelling of non-English language names, film titles and terms, an area which is often found to be the Achilles' heel of many comparable publications. Cook's film history focuses predominantly on the narrative film (the author reminds the reader of this fact more than once). For this reason, the documentary, the animated and the experimental modes of expression are dealt with only marginally. To say that Cook's A History of Narrative Film is the best one-volume English language film history is no exaggeration.

\section{Author Information}

Jan UHDE is Professor Emer. (Film Studies) at the University of Waterloo, Ontario, Canada. Born in Brno, Czech Republic. Graduated (MA) from the Faculty of Arts, Masaryk University, Brno; PhD received at the University of Waterloo, Ontario, Canada. He taught at the University of Waterloo (1970-2012) where he founded a General and Honours BA program in Film Studies at the Department of Fine Arts.

Publications: Latent Images: Film in Singapore Second edition, with Yvonne Ng Uhde (Ridge Books, National University Press of Singapore, 2010); Latent Images: Film in Singapore, with Yvonne Ng Uhde (Oxford University Press, 2000); Latent Images: Film in Singapore CD-ROM (2003, co-author); Vision and Persistence: Twenty Years of the Ontario Film Institute (University of Waterloo Press, 1990) and Ontario Film Institute Programming Activities Index 1969-1989 (Toronto: Ontario Science Centre, 1990). He co-edited the Place in Space: Human Culture in Landscape (Proceedings from the Second International Conference of the Working Group "Culture and Landscape" of the International Association of Landscape Ecology, Pudoc Scientific Publishers, Wageningen, Holland, 1993). Jan Uhde has published articles and reviews in several countries (including Canada, USA, Germany, Italy), participated in international juries at film festivals and presented papers at international conferences in North America and Europe. In 1998/99, he was a visiting researcher at the School for Film and Media Studies, Ngee Ann Polytechnic, Singapore. 


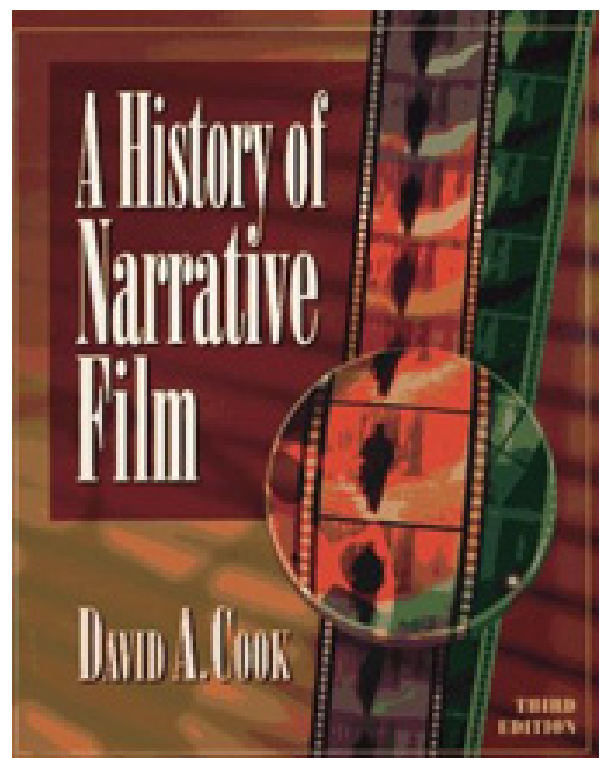

Figure 1: BY: David A. Cook \ PUBLISHER: Norton I YEAR: 1996 ๆ PAGES: 1090pp. ๆ ISBN: 0-393-96819-7 (Pbk.)

His professional and research interests focus on Singapore cinema; the identification and distancing mechanisms of the film viewer; the non-authored modifications and manipulation of films; and specific aspects of film history, including the Central European cinema.

He founded KINEMA in 1993. 